Article

\title{
Mapping Political Discussions on Twitter: Where the Elites Remain Elites
}

\author{
Chrysi Dagoula \\ Center for Media and Journalism Studies, University of Groningen, 9712 EK Groningen, The Netherlands; \\ E-Mail: c.dagoula@rug.nl
}

Submitted: 30 September 2018 | Accepted: 5 February 2019 | Published: 21 March 2019

\begin{abstract}
This article compares digital arenas such as Twitter with the principles prescribed by the bourgeois public sphere, to examine how close or far these arenas are from Habermas' original concept. By focusing on one of the criteria, the current influence of elites on political debate, it discusses the Habermasian principles of general accessibility and non-dominance of the elites as prerequisites for a functioning public sphere. This study finds that even though there are few access restrictions on Twitter and despite the fact that no one, in principle, is excluded from the platform, there is no apparent elimination of privileges and the elites maintain their elite status within its borders. Methodologically, the article relies on empirical research of hashtagged exchanges on Twitter during the General Elections in the United Kingdom in 2015. Through the mapping of Twitter as a synthesis of dialogic arenas, it explores the elite-focused discourse and the vocal actors in the stream, underscoring that the presence of the elites, even in an indirect way. Drawing on these elements, the article argues for a reconceptualization of the normative perception of the public sphere, suggesting the notion of exclusion is a complex issue that includes expanding notions of publics to also include those topics being discussed. Finally, it focuses on the significance of journalism in relation to political dialogue and argues that the move towards less elitecentered arenas largely depends on journalism.
\end{abstract}

\section{Keywords}

democracy; digital public sphere(s); elites; Habermas; journalism; political arenas; Twitter

\section{Issue}

This article is part of the issue "Journalism and Social Media: Redistribution of Power?", edited by Marcel Broersma and Scott Eldridge II (University of Groningen, The Netherlands).

(C) 2019 by the author; licensee Cogitatio (Lisbon, Portugal). This article is licensed under a Creative Commons Attribution 4.0 International License (CC BY).

\section{Introduction}

The emergence of social media platforms was accompanied by "a fresh wave of technological optimism" (Loader \& Mercea, 2011) that underlined the potential of these platforms having a democratizing effect on political dialogue, by providing open and accessible arenas. Such democratic promise also caused a renewed interest on public sphere theory, resulting in a polarized set of reactions, ranging from euphoric commentary on their potential to pessimistic predictions of its democraticizing force (Papacharissi, 2010, p. 10). Such approaches took Habermas' (1989) theory of the public sphere as a starting point, regarding it as a guiding map for successful deliberation, as it offers the normative basis to study the nature and the structure of the political debates within digital arenas. This article embraces the same starting point. In unpacking the principles of the bourgeois public sphere, and transforming them into measurable criteria, this work examines the extent to which current contemporary arenas are close to the Habermasian ideal, shifting the dialogue from questioning whether the Internet is a digital public sphere towards tracing manifestations of the public sphere online, addressing the extent to which certain arenas are closer or further from the vision of a bourgeois public sphere which Habermas proposed.

This article specifically focuses on the criteria of general access to the arenas of dialogue, on the multiplicity of topics discussed, and on the elimination of privileges, as the notion of exclusion is one of the most contested areas when it comes to the bourgeois public sphere. Drawing on this extensive criticism on the concept, set against the promises of inclusion which accompanied new digital participatory arenas, this work suggests that the is- 
sue of exclusion and inclusion is far more complex than has been presented in the related academic literature. In other words, any discussion on the inclusive or exclusive character of digital arenas requires research not only to trace inclusiveness in terms of who participates (publics), but also in relation to what this participation is about, in terms of the nature of the topics and the quality of the dialogue. Finally, it focuses on the role of journalism and its power to not only affect how political dialogue is conducted within the digital arenas, but also to move these arenas closer to the bourgeois model.

Habermas' theory has been contested extensively, either by criticizing its flaws, or by dismissing the concept entirely as insufficient. Such criticism provides us with two options: either to heavily oppose to the concept by focusing on its lack of flexibility to adapt to different societal needs, or to regognize the value of the concept as "a site of information, discussion, contestation, political struggle, and organization" (Dahlgren, 2005, p. 148; Kellner, 2000, p. 12) that enables citizens to "remain plugged into the daily routines of democratic governance and public affairs" (Papacharissi, 2010, p. 114), and therefore to move forward on its reconstruction (Fraser, 1990), its reposition, and its redefinition (Allen, 2012; Dahgren, 2005; Kellner, 2000). Taking the second route, this study adheres to the normativity of Habermas' concept. However, it uses the normative aspect in order to consider a model of the ideal public sphere that is independent from the societal and historical context. In other words, in considering a normative model of political deliberation that builds on both Habermas' theory and on Fraser's criticism of the same, it becomes possible to derive from the normative model a means of comparison for the contemporary dialogic arenas.

As such, this research aims to offer a different conceptual approach from predecessors. First, it addresses the potentiality of digital media to revive democracy, a potential emphasized by both techno-optimists and techno-pessimists. To do so, it presupposes that the public sphere is an open, adaptable and flexible concept-"a metaphor, which when it is materialized, may take several shapes and forms and adopt multiple incarnations" (Papacharissi, 2010, p. 119). This shifts focus from the public sphere per se to its structural transformations and on the factors that led to the formation of the public sphere; in other words, that its structural transformation still exists and still causes structural transformations of the concept.

This article also builds an empirical approach that moves beyond those taken so far (Dahlgren, 2005; Papacharissi, 2002), and it contributes to the methodological approaches by tracing the pre-requisites of the ideal bourgeois public sphere on Twitter. Specifically, in mapping the presence of elites and arguing for the complexity of the aspects of exclusion and inclusion, this article proposes the following set of criteria in assessing the public sphere online: the openness of the social networking platform; the limitations on the discussed topics; and the hierarchical form of interaction. It examines the presence of dominant elite actors, defined here as governing elites as a societal classification which points to "groups of people who either exercised directly or were in a position to influence very strongly the exercise of, political power" (Bottomore, 1993, p. 3). While theoretically the wider goal concerns the reconceptualization of the concept, empirically, each of the criteria offers insightful observations on political dialogue online.

\section{Literature Review}

\subsection{Habermas, the Public Sphere and the Reconceptualization of the Concept: The Issue of Exclusion}

Habermas' ideal version of the public sphere was a direct consequence of the emergence of radical new ideas that appeared in 18th century, characterized by Enlightenment values of equality, freedom, and justice. The bourgeois public sphere that formed in this context was conceived as an assemblage of private individuals who formed a public body-a new stratum of bourgeois people arose and occupied a central position within the "public" (Habermas, 1989). The institutions that constituted this public sphere varied in many ways: in size, the composition of the participants, the ways that the proceedings were conducted, and the climate for debates. However, the institutions shared some criteria as well, among which the preservation of some kind of social interchange that, "far from presupposing the equality of status, disregarded status at all" (Habermas, 1989, pp. 36-37). Among these institutions, the 18th century coffeehouses are particularly important: for Habermas they embodied the realization of his concept. These were the social spaces that offered the opportunity for social gatherings, for rational-critical debate, and ultimately for the formulation of public opinion. The notion of the coffeehouses is equally central to this article, as they emphasize the metaphoric essence of the concept, its flexibility, its contribution to the emergence of journalism and to the enhancement of the comprehension of how journalism is defined, even in contemporary times (Conboy, 2004, p. 50; Örnebring, 2010, p. 68). They are also a form of arena with specific premises, and these premises are the basis for the empirical study here.

According to Habermas, the bourgeois public sphere offered a guarantee of equal participation as there was a process of transformation from the "subjectum" (in a way, the subordinate) into "subject" - from the recipient of commands to the contradicting opponent (Habermas, 1996, p. 81). Habermas underlines in this process a model of norms and modes of behavior, including: a) general accessibility, b) elimination of all privileges, and c) discovery of general norms and rational legitimations (1974, p. 51). This model is evident across Habermas' work: for example, the German phrase he used (Öffentlichkeit) which has become defined as "the 
public sphere" is partially consisted by the term publicity in the sense of openness and access. Webster (2006) similarly summarises the key features of the bourgeois public sphere as having open debate, critical scrutiny, full reportage, increased accessibility, independence of actors from economic interest and state control.

Turning to the topic of elites, Habermas' theory addresses these in terms of the feudal powers of the past, expressed through the notions of hierarchy, tradition, and respect for authority (McKee, 2005). These feudal elites were absent from the deliberative processes in the coffeehouses. Habermas referred to them as "governing elites" - a term that offers a societal classification, pointing to "groups of people who either exercised directly or were in a position to influence very strongly the exercise of political power" (Bottomore, 1993, p. 3). The connection with democracy here is telling: this approach to defining elites has as its main premise that, for a democratic dialogue to exist, it must be in accordance with the democratic principle that "power lies with the people" (Held, 2006, p. 2), where "all members are to be treated as if they were equally qualified to participate in the process of making decisions about the policies the association will pursue" (Dahl, 1998, p. 37). Within political arenas, past and present, this principle is expressed through the "empowerment of the people's voice" (Green, 2010), literally or metaphorically. In Dahl's words, this clearly indicates that "all members are to be treated as if they were equally qualified to participate in the process of making decisions about the policies the association will pursue" (1998, p. 37). From this, at least in principle, hierarchy should be non-existent amongst the members of a democratic society.

According to this line of reasoning, the dominance of elites in public dialogue has been regarded as a way to weaken and undermine the broader participation of the public. For example, the significant development that mass media underwent in the 20th century led the conventional political systems to embrace a media model where political communication was transmitted through elites within an "increasingly closed system" where the audience was largely a body of passive spectators (Bruns, 2008, p. 73). Considering present day circumstances, we could refer to the bourgeois property holders as existing in the form of bourgeois computer holders. As Papacharissi writes: "In this virtual sphere, several special interest publics coexist and flaunt their collective identities of dissent, thus reflecting the social dynamics of the real world", adding this vision of the true virtual sphere "consists of several spheres of counter publics that have been excluded from mainstream political discourse, yet employ virtual communication to restructure the mainstream that ousted them" $(2002$, p. 21). Herein we shift from speaking of a non-hierarchical ideal, towards something more fragmented, with boundaries between spheres of publics.

Along these lines, Habermas' work has been heavily criticized over the years, especially when it comes to the notion of exclusion and the perception of the public sphere as a singular sphere, which ignores the existence of a multiplicity of arenas and publics. Acknowledging this multiplicity of spheres and the need for their inclusion would have reflected a "recognition of social complexity and sociocultural diversity" (Asen, 2000, p. 425; Susen, 2011). In addition, by ignoring the multiplicity of arenas (and consequently of publics), Habermas' conceptualisation underestimates the sociological significance of the alternative (e.g., of publics). Fraser suggests Habermas' "single overarching universal public sphere that is necessary for a well-functioning democracy" (1990, p. 66), should be contrasted with a multiplicity of counter public spheres. She further argues that Habermas idealizes the liberal public sphere by excluding several parts of the general public and subsequently fails to examine the non-bourgeois public spheres and their conflicting relationships (between the so-called counter-publics), which were apparent not only in the 19th or 20th century, as Habermas supports, but from the first appearance of the bourgeois public sphere (Eley, 1992; Fraser, 1990).

Much of the criticism against Habermas followed Fraser's lead: Kellner (2000) for instance, underlines that while the public sphere is "a liberal and populist celebration of diversity, tolerance, debate and, consensus, in actuality, the bourgeois public sphere was dominated by white, property-owning males" $(2000$, p. 5). In a similar vein, Milioni divides exclusion into three categories: a) class exclusion b) exclusion of other forms of expression and c) gender exclusion (2006, p. 32). Milioni also underscores the self-refuting way in which Habermas perceives the public sphere because it violates the basic principle of the public sphere: that of general accessibility. Habermas, himself, engages with these criticisms and, with reference to exclusion, he underlines that "from the beginning a dominant bourgeois public collides with a plebeian one" and that "he underestimated the significance of oppositional and non-bourgeois public spheres" (1992, p. 430).

Despite the criticism, scholars disagree with the complete rejection of the public sphere concept-Fraser, for instance, argues that it is preferable to reformulate Habermas' bourgeois model and develop an alternative post-bourgeois conception (as cited in Allen, 2012). She further proposes areas for reconstruction of the original concept. Picking up on this line of thinking and by situating these discussions in a contemporary context, focusing especially on digital arenas, this article questions the extent to which new social spaces adhere to the same rules and norms as the ideal version of the public sphere that Habermas visualized, as well as the extent to which these comply with the criticisms on the exclusion (as well as the type of exclusion).

\subsection{Twitter: An Opportunity for Inclusion?}

Much of the debate on the democratizing effect of new platforms has been connected with their promises of in- 
clusion, and of expanding participation. However, in this discussion the notion of exclusion has been shown to be much more complex. This turns our attention to Twitter. Twitter has presented itself as an open social networking space that enables Internet users to track breaking news on any occasion (Bruns, 2012), with profiles that can be public and unlocked and accessible to anyone, registered or non-registered (Huberman, Romero, \& Wu, 2008). Likewise, Twitter's official website indicates that there are more than 302 million users per month and more than 500 million tweets posted per day. This is reinforced by its strong journalistic dynamic (Dagoula, 2017), and by the fact that Twitter could be considered an ambient news environment, an arena that always contains news, or an "awareness system" in which news information is received in the periphery of users' awareness and does not require their cognitive attention (Hermida, 2010, p. 301), that "creates social awareness streams that provide a constantly updated, live representation of the experiences, interests and opinions of users" (Hermida, 2014, p. 360). Taking into account the perception of the bourgeois sphere, in which the "circulation of information" was central to its existence (Fraser, 1990), it could be argued that Twitter fits in this description.

On Twitter there are only a few access restrictions and in principle no one is excluded. It is now considered as an increasingly integral element of new media information cycles (Nielsen \& Schroder, 2014). As Chadwick points out, in the new political information cycles that exist within the current hybrid media system, Twitter offers opportunities for non-elites to affect news production through "timely interventions and sometimes direct, one-to-one, micro-level interactions with professional journalists" (2013, p. 89). Chadwick also notes that ordinary citizens are enabled, using digital technologies, to affect the meaning and flow of information (2013, p. 89), prompting a series of questions that concern not only the effect of the non-elite interventions on the agendasetting, but also the presence of the elites (and the manifestations of this presence) in the political dialogue that takes place in networked platforms, such as Twitter.

To understand Twitter's significance as a digital political arena, new mediated spaces need to be regarded as internal parts of the non-digital world, which citizens use and inhabit (Chadwick, O'Loughlin, \& Vaccari, 2017), and where digital and non-digital worlds are not dichotomized but interrelated. The full integration of digital arenas into non-digital ones indicates the existence of an expanded global arena, where time and space restrictions are nullified, in a way that the McLuhan's global village is partly realised as much in terms of connectedness, as in terms of awareness of those others in the village (Dagoula, 2017). In this context, technology is regarded as architecture-as the environment that enables users to become civically engaged (Papacharissi, 2011, p. 10). What is more, Twitter sits within a polymedia environment (Miller et al., 2016), where it is not an isolated platform, but part of a multiplicity of platforms. Madianou and Miller employ the term "polymedia", an approach that highlights that none of these platforms can be properly understood if considered in isolation - the meaning of each one is relative to the others (2011; Miller et al., 2016, p. 4).

However, this coin has another side, and scholars have been arguing about the openness of the network since its emergence in 2006. Research has shown that there is a digital divide among Twitter users and suggests that especially in the United Kingdom and in the United States: "Twitter users are disproportionately members of elites in both countries", in the sense that they are young, wealthy and well educated (Blank, 2017). Young (2002) draws on Fraser and underlines that "in societies with social and economic inequalities, when there is a public sphere it tends to be dominated, both in action and ideas, by more privileged groups. Even though access may be the same for all, the greater resources of wealth, power, influence, and information make access easier for some than others. The interests, opinions, and perspectives more associated with the privileged social actors, then, tend to monopolize discourse in the public sphere" (Young, 2002, p. 171). Fuchs echoes this argument by discussing "the asymmetrical power of visibility on Twitter" (2014, p. 191), pointing to a dominance of the elites (in a more expansive sense of the term) not only in terms of followers, but also in terms of visibility of their tweets.

However, when regarding tweets as "opinion-rich sources", it becomes apparent that although they may not yet represent the society as a whole, they do give a glimpse of a specific influential sector of society (Lutz \& du Toit, 2014). If perceiving social networking platforms as a miniature model of society, it could then be argued that the complete elimination of social inequalities is rather utopic. Therefore, any reconstructed model of the public sphere should seek as much inclusion as possible. Through the comparison of these platforms with the bourgeois public sphere it becomes possible to evaluate the extent to which these approach Habermas' normative requirements. However, the suggestion here is that inclusion should be assessed on another level as wellbeyond actors to also consider the topics discussed. Asen similarly prompts scholars "to seek the counter of counter-publics", in "its articulation through alternative discourse practices and norms" (2000, p. 428), and Young suggests that counter-publics "can have dual functions. On the one hand, the counter-publics can provide sites and fora for members of the subordinated group toraise issues among themselves and discuss them, formulate analyses and positions, as well as develop aesthetic and discursive modes for expressing their social perspectives, autonomous from dominant discourses" (2002, p. 172). Going back to Habermas, he highlights that all sorts of topics were open to discussion as these institutions allowed the "problematization of areas that until then had not been questioned" (1989, pp. 36-37), pointing another perception of general accessibility. 
Last but not least, the role of journalism remains crucial in this discussion as inclusion (or exclusion) of topics is connected with the quality of information, which inevitably leads to the role of the press. Fraser (1990) describes the public sphere as a place where information, ideas, and debate can circulate in society and where political opinion can be formed, an argument Curran advances by arguing that if by taking as a premise that "public opinion is to be formed in an arena of open debate", then "the effectiveness of this will be profoundly shaped by the quality, the availability and the communication of information" (Curran, 1991). As Webster (2006) adds, information is also at the core of the public sphere and the media are one of the most important contributors to its effective functioning.

\section{Methodological Design}

Turning to the empirical study, the methodological approach relies on the operationalization of Habermas' normative criteria into measurable qualities, so as to be able to test to what extent these criteria are met on Twitter and to further develop existing approaches to the evaluation of the public sphere. It looks specifically at openness from Habermas' theory in terms of the presence or absence of hierarchies (and therefore elites), as well as the openness of Twitter in terms of the same. It addresses these by examining the nature of publics and dialogues on Twitter, as will be layed out below, surrounding the 2015 UK General Election.

The starting point for this methodolgocial approach is Bruns and Moe's perception of Twitter as a synthesis of dialogic arenas at micro, meso and macro layers. The macro layer is defined by the hashtagged exchanges, the meso as delimited by follower/followee networks, and the micro layer represented by the reply function that includes personal exchanges (Bruns \& Moe, 2014, pp. 16-20). For this article, the analysis focuses on the macro layer-and the hashtagged exhanges between Twitter users. Hashtags are an integral part of Twitter, as they manage to link conversations of strangers together. What is more, Twitter is "more of a stream, which is composed by a polyphony of voices all chiming in" (Murthy, 2013, p. 4), and hashtags act as "imaginary borders" that delimit certain dialogic arenas. As Marwick (2014) put it, Twitter research should be framed as a field site, to avoid losing focus due to its extensive nature. Moreover, hashtags not only provide a diachronic perspective, they are also useful for identifying key participants in a discussion (Bruns \& Burgess, 2012, pp. 805-806)-in this case, they allow research to locate the most vocal actors in the stream.

The choice of hashtags is also important in purely Habermasian terms: both the macro and the meso layer constitute elements of the public dialogue, or as Bruns and Moe note "they encompass a certain degree of publicness" (2014, pp. 16-20). Moreover, the use of hashtags at the macro layer can "aid the rapid assembly of ad hoc issue publics" (2014, p. 18), especially when tweets are marked by a topical hashtag, as "tweeting to a topical hashtag resembles a speech at a public gathering...of participants who do not necessarily know each other, but have been brought together by a shared theme, interest or concern" (Bruns \& Moe, 2014, p. 18). Here attention to hashtags relates, in a sense, to social gatherings reminiscent of coffeehouses.

Focusing on the General Elections in the United Kingdom that took place on 7 May 2015, the Twitter data gathered includes tweets, using hashtags, posted from 30 March 2015 (the dissolution of Parliament) to 31 May 2015 (24 days after the elections). This focuses on the period of heightened political interest. Tweets using the two most popular hashtags were collected; these were \#GE2015 and \#GE15 (https://www.hanovercomms.com). After filtering and removing duplicates, the total sample for each hashtag and tweets consists of 149,287 and 95,629, respectively, collected using Tags 6.0 software. This software uses Twitter's Application Programming Interface (API), which can be used for tracking current activity by users or of specific keywords (Bruns \& Burgess, 2012, p. 804). This research embraces Bruns and Burgess' argument that:

The data [that emerge through the participation in hashtag conversations] must be understood as a reasonably representative sample rather than a comprehensive dataset of activities....Datasets in particular are weighted considerably towards the most engaged subset of Twitter users. (2012, p. 804)

The sample was analysed both textually as thematically. Drawing on Mason (2002), who suggested that the choice of documents is based on an acceptance of the fact that they are meaningful constituents of the social world, this research adjusts this claim to the Twitter platform. To map the presence of elites and to be able to trace the notions of exclusion and inclusion, this article focuses on three criteria:

- The openness of the network: to be a functioning digital sphere (or spheres) Twitter should be open to all citizens, without technological limitations. Empirically, analysis examines the diversity of users that participate in the discussion through the hashtags \#ge2015, \#ge15.

- The restriction of the discussed topics: for a functioning digital public sphere(s) there should be no restrictions in the choice of the discussed topics. Empirically, this is operationalized by qualitative thematic and textual analysis of the tweets, which facilitates the aggregation of reactions related to the elections.

- The non-hierarchical form of interaction: for a realized digital sphere(s), there should be a nonpresence of prominent elite actors. Empirically, frequency analysis is employed, following previous 
studies, to highlight which actors and terms dominate the dialogue (Papacharissi, 2014).

In terms of limitations, there are a few considerations. Even though tweets were gathered on a daily basis, they were collected in an asychronous manner, meaning that deleted tweets may be excluded. In addition, Twitter API restrictions set a strict limit for gathering of tweets, as these can only be collected in a short time frame with extra daily limitations (Puschmann \& Gaffney, 2014). Lastly, even though the scope of the present article is limited to a specific national context, the focus on elections does not act in a restrictive way: electoral periods are not only periods with high political interest, especially from a journalistic perspective, but in contemporary societies where representative democracies prevail they can also be considered the epitome of democracythey are those specific occasions that offer the opportunity for participation in democratic processes. As such, the choice to examine political dialogue, on Twitter, during an electoral period, lies primarily in their significance as a democratic condition. As Maireder and Ausserhofer note, within social networking sites such as Twitter "a public negotiation of the meaning of the political events" is witnessed (2014, p. 316), providing a clear connection with the Habermasian public debate and the principle of publicity.

\section{Findings and Discussion}

\subsection{The 'Publics'}

Drawing from the analysis of the accounts using these hashtags, we can first look at who makes up the 'publics', including dominant actors and the ways in which they position themselves in the dialogue. The openness of the network allows for a variety of actors to participate in the streams. However, the presence of Twitter users is massively overshadowed by the presence of bots. The frequency analysis on the collected material as well as the sampling and filtering of the top 100 accounts show that both streams are dominated by 'the bots' (e.g., @ge2015bot). Bots, as automated information transactions, feed Twitter streams with automated tweets, without any human intervention (Larsson \& Moe, 2015). The following examples showcase the format of these tweets, however, during the time of the analysis, the accounts were no longer available:

- ge2015bot: vmg456: RT C9J: Tomorrow we have the chance to make Scotland's voice heard like never before. \#GE15 \#Voâ€!

- ge2015bot: BigTfromHalfway: RT theSNP: \#GE15: AlynSmithMEP highlights that the SNP will work with others to be a pâ€!

In the case of the first hashtag (\#GE2015), the number of posted tweets sent by a bot account was $13.4 \%$ of the total amount of the collected tweets $(19,985$ tweets). Likewise, in the \#GE15, bot-tweets, $10.5 \%$ of the material $(10,075$ tweets) are from bots. In the first stream, two other bots are also feed the stream with automated information: the @UKElection and @Election2015, which primarily retweet already posted material. In all these occasions, the accounts were deleted from Twitter at the time of the study.

Turning to the most vocal Twitter users using these hashtages, these account for only $0.3 \%$ of overall dialogue, a significant difference when compared to the space bots cover. Qualitatively analyzing these accounts, this echoes Gottfried's argument that while Twitter is populated by a rather larger audience, its most active users are mostly of those who are politically interested (Gottfried, 2014). For example, on the \#GE15 stream, $63.2 \%$ of the fifty studied accounts belong to individual users. These individuals, however, also promote that they are interested in politics in their Twitter biographies, and/or that they support a specific political party. This mirrors the normative discussion of Habermasian coffeehouses, and the preference for openness of standpoint, the consistency of which was primarily by political interested citizens-the bourgeiois stratum (Habermas, 1989).

The most striking finding, though, concerns the absence among these active, political, users of politicians, political parties, and formal political actors, particularly those who were contestants in the 2015 General Elections. Also striking was the degree to which journalists and media are absent, with the exception of @politicshour and @ConversationUK, on the \#GE2015 stream.

These results suggest the platform users have a clear way to communicate through the network and to politically express themselves without engaging such actors. This demonstrates as well how the potential for participating in political discussions on Twitter is open-where, in principle, no one is excluded-and that there is no direct dominance of the governing elites in the streams. However, it does not indicate a low presence of such actors-as they are present in an indirect way. For example, elite accounts are not only popular in terms of followers (active audience), but also in terms of retweets they receive (passive audience). These two indicators suggest that the are in a central place in the platform.

\subsection{The 'Topics'}

Another way of understanding publics is through making sense of the topics discussed. Through the thematic analysis of the collected tweets, that demonstrates an elitefocused tweeting, especially when it comes to the power or governing elites. As expected, tweets analyzed mostly included words related to the General Election. However, the thematic analysis demonstrates a low variety of themes, which mostly concentrate on media and political actors, pointing to the question of inclusiveness on the platform, when considered in terms of discussed topics. 
For instance, under the \#GE2015 hashtag, David Cameron is mentioned 4,999 times, the Conservative Party is mentioned 17,786 times, the Labour Party 14,922 times, and the Scottish National Party 10,076 times. These findings point to a preference to elitecentral discussions, focused on politicians and political parties, showcasing an indirect (i.e., without specific @mentions), yet significant, presence of elites. As examples:

- $36 \%$ of people who voted, voted Tory. That's less than a quarter of public as a whole. This is not democracy. \#GE2015

- Look, the Tories won: it's called a democracy. I don't like it either but violence and vandalism is inexcusable. \#GE2015

- Well done Prime Minister \#DavidCameron. You fought a good battle. \#GE2015

- Nigel Farage says new \#Ukip voter is young and working class. But will he resign? \#GE2015

- WOW. Even the exit poll underestimated the Tories chances! UKIP got only one seat, without Farage. What a great night for Cameron. \#GE2015

- For those who blame \#Sturgeon on \#Cameron's victory: it's called \#FirstPastthePost You are welcome. \#GE2015

- \#Election2015: UK wakes up to Tory majority \#GE2015

- These protests against the final results of the General Election- it was a clear win- the Conservatives won fair and square \#GE2015

- Wow. Three party leaders facing exits today. \#GE2015 \#GE15 @UKIP @UKLabour @LibDems who will be missed?

Journalistic actors are also not included in the most popular mentioned words, apart from BBC's accounts, which are mentioned 12,458 times, primarily in relation to the BBC Debate, reinforcing the argument of "dual screening" (Vaccari, Chadwick, \& O' Loughlin, 2015), where Twitter acts as a real-time platform that feeds comments and reactions into the coverage of political events, broadcasted by other media platforms. In a similar vein, Jungherr (2014, p. 242) notes that Twitter appears very receptive to media events, as the volume of the messages rises sharply in reaction to a scheduled event, such as the debate of the leading candidates-echoing the argument that the Twitter acts as a platform where elitefocused debate is taking place.

Twitter users, however, mention individual journalists as an attempt to engage in dialogue with them. However, more often than not, these prompts are made without a response, as journalists' use of the reply function is very low; when used, it is used to engage in conversation with specific actors: politicians, journalists, other media actors, in a form of intra-elite conversation. Such an elitist approach has also been observed when studying the tweets of media organiza- tions: in the context of General Elections 2015, BBC, Daily Mail, Guardian and Telegraph mention almost exclusively other accounts belonging to their organization (e.g., @BBCElectionbot, @BBCr4today, @FeMail, @GuardianWitness, @guardianworld), journalists working for the medium, and rarely politicians (e.g., David Cameron, Ed Miliband, Nigel Farage) (Dagoula, 2017, p. 157).

Going further, a large number of tweets are presented in the format of political commentary, with users presenting their comments in line with traditional, if not exclusive journalistic functions; these include bearing witness or holding power to account (Picard, 2014, p. 278). This journalistic use of the medium reveals users' willingness to provide information or criticism on the elites, on policies, and on processes like the elections. This underlines a form of political expression, with Twitter users commenting, opposing, and adding their voices to Twitter's political commentary stream, as shown by these examples:

- 3) I argued beginning of April that a majority CON/LAB needed to face down SNP in House of Commons. Now CON listen to @PaulGoodmanCH \#GE2015

- @David_Cameron 0 hour contracts? I'm guaranteed 0 hours, how am I meant to build a future for myself? It was easier on the dole. \#ge2015

- This is David Cameron-The man who forced a Hospital to open a food bank for sick children \#GE2015

- $24 \%$ of the voting population voted Conservative (37\% of $66 \%$ turnout). Maintaining the current system is morally bankrupt politics. \#GE2015

- \#BBC Forecasting Conservatives will finish with 331 seats! \#Wow \#GE2015 A huge victory for common sense.

- Lots saying 'I don't even know u anymore Britain'...u clearly didnt know it before, or ud know its basically a Conservative country \#GE2015

This indirect impact or indirect involvement of the elites, and notably governing elites, indicates a shift on the discussion on the democratic dynamic of Twitter. While primarily the emphasis was placed on issues of inclusion of different publics, it is now moved to the inclusion of discussed themes. Twitter is arguably an open network and in principle access is guaranteed to everyone and no one is excluded, however, when observing closer, hierarchy (or, hierarchical classification) is still present within its borders. Likewise, if the presence of the elites is directly minimized (in terms of their actual participation in the dialogue), this could not be translated to a complete absence. Elites are not dominating as actors, but they do as themes of discussion.

\section{Conclusive Remarks}

Young writes that "one of the purposes of advocating inclusion is to allow transformation of the style and terms 
of public debate and thereby open the possibility for significant change in outcomes" (2002, p. 12). This article discusses the notions of exclusion and inclusion in digital political dialogue in the context of the public sphere theory. It argues that for functioning digital political arenas it is not only necessary to apply Habermas principle of general accessibility and non-dominance of the governing elites, but it is also crucial that this openness is reflected in the discussed themes-despite the simultaneous existence of particular thematic debates within and across broader domains (Bruns \& Highfield, 2016). Twitter is considered an open network, acting in a way on what Arendt describes as environment that "the insider and the outsider alike have the ability to appear and speak for themselves in political public spheres" (as cited in Breese, 2011, p. 137).

The overall aim is to consider reconceptualization of public sphere theory through the lens of normativity and the development of a model that will offer criteria which can be tested within current arenas to measure the degree to which these adhere to the ideal public sphere (Dagoula, 2017). Therefore, this research argues for the reconstruction of the normative model, embracing Arendt's appreciation that political public spheres could be reinvigorated in the contemporary world (Zerilli, 2005). This discussion comes through the focus on the structural transformations, which directly affect the consistency and the structure of the current arenas. It also comes through the analysis of public sphere's dimensions that allow the ideal model to act as a measure for comparison.

This normative perception should also take into account the extensive criticism the Habermasian public sphere has endured, and notably those critiques which concern the notion of exclusion, and juxtapose these to the digital promises of inclusion made by new social networking platforms. Regarding exclusion specifically, even though the complete elimination of social inequalities is rather utopic, the normativity of the model allows scholars to aim towards considering as much inclusion as possible. As such, an inclusive normative model should include not only the publics but also the topics in its evaluation of a public sphere, both in terms of it nature and in the quality of the discourse, which (contra Habermas) is emotionally charged with a low degree of rationality, as the examples in the findings show. What is more, the research while focused on Twitter, considers its findings as possibly contributing to a larger media ecology, where Twitter is only one of many available arenas. As such, any understanding, or revision of the public sphere concept, should refer to public spheres, rather than to the public sphere, taking into account the multiplicity of overlapping, unequal publics (Breese, 2011). Furthermore, it should also reflect the "range of institutions, groups, and media, that form public spheres of discourse, action, representation, and criticism" (Breese, 2011, p. 134). Likewise, the elite-focused debate, even when in alignment with the bourgeois version of the public sphere and its attention on current affairs, should also reflect the multiplicity of publics and its interests. Naturally, this implies that, for an inclusion of counter-topics, the inclusion of counter-publics is presupposed. However, the findings here highlight that the notion of exclusion is a far more complex issue.

At this point, the role of journalism becomes very important. A more sophisticated use of Twitter by various media actors would greatly benefit the political functions of the new mediated arenas. To return to Habermas, he put the press at the center of his concept, by highlighting its unique explosive power (1989) that nourished the debate by presenting critical reporting and by submitting political issues to critical discussion. The press was a catalyst for the circulation of information and for Habermas was the "most eminent institution of the public sphere" (Peters, 1993). In previous work, I argue that Twitter offers the opportunity to the journalistic actors to have an essential role, either by echoing these voices in their other journalistic channels off Twitter, by filtering the information and promoting important topics on the platform, or by positioning themselves in the discussion and performing their journalistic practices (Dagoula, 2017, p. 167). Or, in Dahlgren's words, it is necessary to explore "to what extent the media, by performing their journalistic role, can inform citizens adequately, put their responses into public debate, and encourage them to reach informed decisions about what courses of action to adopt" (Dahlgren, 2005). Putting this within Habermas' theory of the public sphere, the press is the force that should encourage the public(s) to act on their conscience and capacity as citizens and not as consumers, but also part of the machinery that could lead to meaningful democratic societies, the premise of which is an informed electorate (Papathanasopoulos, 2011). As such, and to add to Fraser's (1990) proposal for a reconstructed normative theory of the public sphere, any new approach should have journalism in a central position.

\section{Conflict of Interests}

The author declares no conflict of interests.

\section{References}

Allen, A. (2012). The public sphere: Ideology and/or ideal? Political Theory, 40(6), 822-829.

Asen, R. (2000). Seeking the "counter" in counterpublics. Communication Theory, 4, 424-446.

Blank, G. (2017). The digital divide among Twitter Users and its implications for social research. Social Science Computer Review, 35(6), 679-697.

Bottomore, T. (1993). Elites and society (2nd ed.). London: Routledge.

Breese, E. (2011), Mapping the variety of public spheres. Communication Theory, 21, 130-149.

Bruns, A. (2008). Life beyond the public sphere: Towards a networked model for political deliberation. Infor- 
mation Polity, 13(1/2), 65-79.

Bruns, A. (2012). Ad hoc innovation by users of social networks: The case of Twitter. Vienna: Centre for Social Innovation.

Bruns, A., \& Burgess, J. (2012). Researching news discussions on Twitter. Journalism Studies, 13(5/6), 801-814.

Bruns, A., \& Highfield, T. (2016). Is Habermas on Twitter? In A. Bruns, G. Enli, E. Skogerb $\varnothing$, A. O. Larsson, \& C. Christensen (Eds.), The Routledge companion to social media and politics (pp. 56-73). New York, NY: Routledge.

Bruns, A., \& Moe, H. (2014). Structural layers of communication on Twitter. In K. Weller, A. Bruns, J. Burgess, M. Mahrt, \& C. Puschmann (Eds.), Twitter and society. New York, NY: Peter Lang.

Chadwick, A. (2013). The hybrid media system. Oxford: Oxford University Press.

Chadwick, A., O'Loughlin, B., \& Vaccari, C. (2016). Why people dual screen political debates and why it matters for democratic engagement. Journal of Broadcasting \& Electronic Media, 61(2), 220-239.

Conboy, M. (2004). Journalism: A critical history. London: Sage Publications.

Curran, J. (1991). Rethinking media as a public sphere. In P. Dahlgren \& C. Sparks (Eds.), Communication and citizenship: Journalism and the public sphere. London: Routledge.

Dagoula, C. (2017). The ongoing structural transformations of the digital public sphere(s): The role of journalism (Unpublished doctoral dissertation). Sheffield, University of Sheffield. Retrieved from http://etheses.whiterose.ac.uk/18499

Dahl, R. A. (1998). On democracy. New Haven, CT: Yale University Press.

Dahlgren, P. (2005). The internet, public spheres, and political communication: Dispersion and deliberation. Political Communication, 22(2), 147-162.

Eley, G. (1992). Nations, publics, and political cultures: Placing Habermas in the 19th century. In C. Calhoun (Ed.), Habermas and the public sphere. Cambridge, MA: MIT Press.

Fraser, N. (1990). Rethinking the public sphere: A contribution to the critique of actually existing democracy. Social Text, 25/26, 56-80.

Fuchs, C. (2014). Social media: A critical introduction. London: Sage Publications.

Gottfried, J. (2014). Facebook and Twitter as political forums: Two different dynamics. Pew Research Center. Retrieved from http://www.pewresearch.org/facttank/2014/11/12/facebook-and-twitter-as-politicalforums-two-different-dynamics

Green, J. E. (2010). The eyes of people. Oxford: Oxford University Press.

Habermas, J. (1974). The public sphere: An encyclopedia article. New German Critique, 3, 49-55.

Habermas, J. (1989). The structural transformation of the public sphere, An inquiry into a category of bourgeois society. Cambridge, MA: MIT Press.

Habermas, J. (1992). Further reflections on the public sphere. In C. Calhoun (Ed.), Habermas and the public sphere. Cambridge, MA: MIT Press.

Habermas, J. (1996). Three normative models of democracy. Democracy and Difference, 1(1), 21-31.

Held, D. (2006). Models of democracy. Cambridge: Polity Press.

Hermida, A. (2010). Twittering the news. Journalism Practice, 4(3), 297-308.

Hermida, A. (2014). Twitter as an ambient news network. In K. Weller, A. Bruns, J. Burgess, M. Mahrt, \& C. Puschmann (Eds.), Twitter and society (pp. 359-372). New York, NY: Peter Lang.

Highfield, T. (2016). Social media and everyday politics. Cambridge: Polity Press.

Huberman, B. A., Romero, D. M., \& Wu, F. (2008). Social networks that matter: Twiter under the microscope. First Monday, 14(1), 1-9. Retrieved from: http:// firstmonday.org/ojs/index.php/fm/article/view/2317 $/ 2063$

Jungherr, A. (2014). The logic of political coverage on Twitter: Temporal dynamics and content. Journal of Communication, 64, 239-259.

Kellner, D. (2000). Habermas, the public sphere, and democracy: A critical intervention. Retrieved from http://pages.gseis.ucla.edu/faculty/kellner/papers/ habermas.htm

Larsson, A. O., \& Hallvard, M. (2015). Bots or journalists? News sharing on Twitter. Communications, 40(3), 361-370.

Loader, B., \& Mercea, D. (2011). Networking democracy? Social media innovations and participatory politics. Information, Communication \& Society, 14(6), 757-769.

Lutz, B., \& du Toit, P. (2014). Defining democracy in a digital age: Political support on social media. London: Palgrave Macmillan.

Madianou, M., \& Miller, D., (2011). Migration and new media: Transnational families and polymedia. London: Routledge.

Maireder, A., \& Ausserhofer, J. (2014). Political discourses on Twitter: networking topics, objects and people. In K. Weller, A. Bruns, J. Burgess, M. Mahrt, \& C. Puschmann (Eds.), Twitter and society (pp. 305-318). New York, NY: Peter Lang.

Marwick, A. E. (2014). Ethnographic and qualitative research on Twitter. In K. Weller, A. Bruns, J. Burgess, M. Mahrt, \& C. Puschmann (Eds.), Twitter and society (pp. 109-122). New York, NY: Peter Lang.

Mason, J. (2002). Qualitative researching. London: Sage Publications.

McKee, A. (2005). The public sphere: An introduction. New York, NY: Cambridge University Press.

Milioni, D. (2006). Mass communication and democracy: Towards a model of democracy in the age of global connectivity (Unpublished doctoral thesis). Thessaloniki, Aristotle University of Thessa- 
loniki. Retrieved from http://phdtheses.ekt.gr/eadd/ handle/10442/18025

Miller, D., Costa, E., Haynes, N., McDonald, T., Nicolescu, R., Sinanan, J., . . . Wang, X. (2016). How the world changed social media. London: UCL Press. Retrieved from https://www.ucl.ac.uk/ucl-press/browse-books/ how-world-changed-social-media

Murthy, D. (2013). Twitter. Cambridge: Polity Press.

Nielsen, K. R., \& Schrøder S. (2014). The relative importance of social media for accessing, finding, and engaging with news. Digital Journalism, 2(4), 472-489.

Ornebring, H. (2010). Technology and journalism-aslabour: Historical perspectives. Journalism, 11, 57-74.

Papacharissi, Z. (2002). The virtual sphere. New Media \& Society, 4(1), 9-27.

Papacharissi, Z. (2010). A private sphere: Democracy in a digital age. Cambridge: Polity Press.

Papacharissi, Z. (2014). Affective publics: Sentiment, technology, and politics. New York, NY: Oxford University Press.

Papathanassopoulos, S. (Ed.). (2011). Media perspectives for the 21st century. New York, NY: Routledge.
Peters, J. D. (1993). Distrust of representation: Habermas on the public sphere. Media, Culture \& Society, 15(4), 541-571.

Picard, R. G. (2014). Twilight or new dawn of journalism? Digital Journalism, 15(5), 1-11.

Puschmann, C., Bruns, A., Mahrt, M., Weller, K., \& Burgess, J. (2014). Why study Twitter.In K. Weller, A. Bruns, J. Burgess, M. Mahrt, \& C. Puschmann (Eds.), Twitter and society (pp. 425-432). New York, NY: Peter Lang.

Susen, S. (2011). Critical notes on Habermas's theory of the public sphere. Sociological Analysis, 5(1), 37-62.

Vaccari, C., Chadwick, A., \& O' Loughlin, B. (2015). Dual screening the political: Media events, social media, and citizen engagement. Journal of Communication, 65(6), 1041-1061.

Webster, F. (2006). Theories of the information society (3rd ed.). New York, NY: Routledge.

Young, I. M. (2002). Inclusion and democracy. Oxford: Oxford University Press.

Zerilli, L. M. G. (2005). Feminism and the abyss of freedom. Chicago, IL: University of Chicago Press.

\section{About the Author}

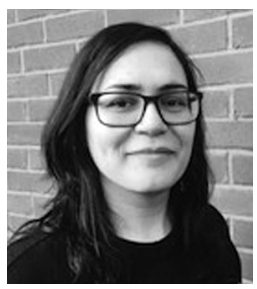

Chrysi Dagoula is an Assistant Professor at the Centre for Media and Journalism Studies at the University of Groningen. Her work focuses on the structural transformations of the public sphere in the digital era, and her areas of expertise include: public sphere theory; journalism and democracy; manifestations of political expression and participation in digital environments; the evolution of political arenas; and the the effect of social media platforms on journalists and media actors. 